ISSN: 0514-7336 — ISSN electrónico: 2386-3943

DOI: https://doi.org/10.14201/zephyrus202086143164

\title{
CASTRAMETACIÓN ROMANA EN LA MESETA NORTE HISPANA: NUEVAS EVIDENCIAS DE RECINTOS MILITARES EN LA VERTIENTE MERIDIONAL DE LA CORDILLERA CANTÁBRICA (PROVINCIAS DE BURGOS Y PALENCIA)
}

\section{Roman castrametation in the Northern Hispanic Plateau: New evidences of military camps in the south of the Cantabrian Mountains (Burgos and Palencia provinces)}

Esperanza Martín Hernández*, Antxoka Martínez Velasco**, Diego Díaz Alonso***, Fernando Muñoz Villarejo**** y Laura BéCARes RodríGuez ${ }^{* * * * *}$

* Dolabra. Cl La Iglesia, 32. 24891 Ruiforco de Torio (León). Correo-e: dolabra@dolabra.es. ID ORCID: https:// orcid.org/0000-0003-1718-7281

** Sociedad de Ciencias Aranzadi. Cl Zorroagagaina, 11. 20014 Donostia-San Sebastián (Gipuzkoa). Correo-e: amartinez@aranzadi.eus; ID ORCID: https://orcid.org/0000-0003-2248-3763

***Arqueólogo. C/ Cabruñana, 40, 3A. 33402 Avilés (Asturias). Correo-e: valdredo@gmail.com. ID ORCID: https:// orcid.org/0000-0001-8334-6629

**** Arqueólogo. Avda. Alvaro López Núñez, 23. 24002 León. Correo-e: info@miscelanea.es. ID ORCID: https:// orcid.org/0000-0002-2439-2913

***** Arqueóloga. Cl Hevia Bolaños, 5. Oviedo (Asturias). Correo-e: becaresespalabraesdrujula@gmail.com. ID ORCID: https://orcid.org/0000-0003-2153-2631

Recepción: 18/06/2020; Revisión: 13/07/2020; Aceptación: 4/11/2020

Resumen: Entre 2018 y 2020 hemos desarrollado, por iniciativa de la Junta de Castilla y León, el Proyecto de Investigación Roma frente a Cántabros y Astures. Su finalidad fundamental ha sido generar un instrumento de gestión, conocimiento y protección que incluyese todos los establecimientos militares romanos localizados en Castilla y León y relacionados con este periodo histórico. El desarrollo del proyecto ha conllevado la introducción, en el catálogo general de yacimientos, de otros campamentos romanos hasta ahora inéditos. De hecho, las labores de prospección y teledetección que hemos llevado a cabo en las provincias de Palencia y Burgos han permitido incrementar en varias decenas el catálogo de recintos militares conocido. En este trabajo, en el que hemos prestado especial atención a los conjuntos identificados alrededor de Herrera de Pisuerga y en la cuenca del Burejo, así como a los presentes en el camino natural entre Sasamón y Abia de las Torres, presentamos un bloque notable. La identificación de estos nuevos emplazamientos proporciona una base sólida que permitirá avanzar notablemente en el conocimiento de la presencia militar romana en esta región entre las guerras cántabras y los ss. I-II d. C.

Palabras clave: ejército romano; guerras cántabras; castra aestiva; asedio; LiDAR; teledetección; vías romanas. 
ABSTRACT: Between 2018 and 2020 we have carried out, on the initiative of the Castilla y León Government, the Research Project Roma frente a Cántabros y Astures. Its main purpose has been to generate a management, knowledge and protection instrument that includes all the Roman military establishments located in Castilla y León and related to this historical period. The development of the project has led to the sum, in the general catalogue of sites, of other hitherto unpublished Roman camps. In fact, the prospecting and remote sensing work that we have carried out in the provinces of Palencia and Burgos has allowed us to increase the catalogue of known military sites by several tens. In this work, in which we have paid special attention to the sites identified around Herrera de Pisuerga and in the Burejo basin, as well as those along the natural route between Sasamón and Abia de las Torres, we present a remarkable block. The identification of these new sites provides a solid base that will allow us to make significant progress in our knowledge of the Roman military presence in this region between the Cantabrian wars and the $1^{\text {st }}$ and $2^{\text {nd }}$ centuries AD.

Key words: Roman Army; Cantabrian Wars; castra aestiva; siege; LidaR; Remote Sensing; Roman road network.

\section{Introducción}

En 2018 le fue encomendada, al equipo que suscribe este trabajo, por parte de la Dirección General de Patrimonio de la Junta de Castilla y León, la revisión y puesta al día de las evidencias existentes de la presencia militar romana en la Comunidad Autónoma de Castilla y León, centrándose el trabajo en las provincias de Burgos, Palencia, León y Zamora ${ }^{1}$. Una actuación que tenía como objetivo realizar una puesta al día que incluyera tanto la recopilación de la bibliografía existente al respecto como la revisión de la información gráfica -fotografías aéreas y datos LiDAR - del estado actual de los yacimientos, además de la situación legal, protección y otros aspectos básicos de los mismos. Finalmente, se realizaron comprobaciones sobre el terreno mediante prospección terrestre y aérea con RPA, con el objetivo de hallar zonas susceptibles de albergar nuevos yacimientos y probar la veracidad de noticias y hallazgos recientes.

1 Queremos agradecer a la Junta de Castilla y León el impulso firme a este tipo de estudios y proyectos. También damos las gracias a A. Ruiz Cabezón y a J. Granados Castro por su desprendida ayuda en el análisis de imágenes. Además, agradecemos a los evaluadores sus valiosas apreciaciones que han permitido mejorar nuestra versión inicial del artículo. Finalmente, queremos expresar nuestro agradecimiento a los compañeros involucrados en el estudio de la Arqueología Militar en el Noroeste peninsular y, especialmente, nos gustaría reconocer al Dr. A. Morillo su paciente y constante ayuda para con nosotros y su interés en facilitar la comprensión y estudio del fenómeno militar hispano.
Entre los resultados más significativos, señalamos aquí la identificación de nuevas estaciones campamentales romanas en diferentes puntos de las provincias de Burgos y Palencia ${ }^{2}$. Este artículo recoge algunas de esas novedades y las conclusiones preliminares del trabajo de investigación derivado del mencionado encargo administrativo.

\subsection{La presencia militar de Roma en el Norte de la actual Comunidad de Castilla y León}

Posiblemente, la conquista de cántabros y astures sea uno de los episodios vinculados a la presencia romana en Hispania más tratados en la historiografía, a pesar de carecer -o quizás precisamente por eso- de evidencias arqueológicas suficientes sobre las que sustentar las hipótesis. Son escasos los recintos campamentales que presentan, al menos, una campaña de investigación y la gran mayoría cuenta con una identificación topográfica o cartográfica como la que aquí se presenta, habitualmente acompañada de una prospección pedestre del entorno, que por fuerza suele resultar infructuosa si no ha sido acompañada de otros medios técnicos. Resulta habitual la extrapolación de datos o el empleo de mensuraciones y dataciones genéricas de los lugares a que se hace referencia al hablar de la conquista. No es baladí la casi inexistencia de programas

2 Actualmente en las provincias de Zamora y León existen otros proyectos de investigación en curso, a cuyos equipos agradecemos sinceramente su ayuda y colaboración. 
sistemáticos de estudio y análisis de los campamentos romanos de la conquista.

Esta afirmación no pretende ser una crítica sobre los trabajos realizados, realmente encomiables desde una perspectiva arqueológica, habida cuenta de los reducidos medios disponibles en todo momento; sino simplemente una constatación de la realidad actual del conocimiento arqueológico sobre las evidencias de la conquista.

Resulta imposible tratar de compilar la bibliografía acerca de la última fase de la conquista de los pueblos hispanos del Norte, por lo que remitimos a recientes trabajos de conjunto (Bolado et al., 2012; Morillo, 2014) y, especialmente, al último congreso monográfico dedicado a este tema (Camino et al., 2015).

Las fuentes clásicas nos informan que, ante la victoria de Augusto y el establecimiento del Imperio, los únicos pueblos aún sin someter en Hispania eran cántabros y astures, por lo que se convirtieron en el necesario foco a pacificar en la Península y el primer objetivo militar del princeps en su decisión de buscar fronteras estables. A este factor, ha de sumarse la riqueza económica de la parte septentrional de Hispania, donde destacan la explotación minera astur y galaica y las facilidades para el comercio que ofrecía la zona atlántica (Morillo, 2002: 68-69; Fernández Ochoa, 2003). Además de la necesidad del propio emperador de consolidar su poder político en Roma mediante una victoria en una guerra de conquista, justificando así tanto el propio conflicto como la presencia de Augusto al frente de las operaciones.

Las principales fuentes clásicas empleadas para seguir este relato son los textos de Floro, Orosio y Dión Casio ${ }^{3}$, sin muchos detalles del desarrollo de las operaciones. El número de legiones implicadas resulta llamativo, precisamente por lo reducido del escenario bélico, habiéndose visto implicadas al menos la legio I Augusta, la II Augusta, la IIII Macedonica, la $V$ Alaudae, la VI Victrix, la $I X$ Hispaniensis, la

3 Desgraciadamente se encuentra perdido el libro 135 de $A b$ Urbe condita de Tito Livio, donde debieron plasmarse gran parte de todos estos pormenores.
$X$ Gemina y la XX Valeria Victrix (García y Bellido, 1961; Morillo, 2005: 23-24).

El período de hostilidades comienza durante el legado de Estatilio Tauro para afianzar el territorio entre el Pisuerga y el Duero en el 29 a. C., al mismo tiempo que controlaba todas las tribus del norte. Los triunfos en años sucesivos de C. Calvisio Sabino y Sexto Apuleyo parecen indicar el buen devenir de dichas operaciones. Será en el año 27 a. C. cuando el propio Augusto se persone en Hispania.

El conflicto bélico se distribuye en dos ejes, uno de los cuales es directamente comandado por el princeps desde la Citerior contra los cántabros y otro desde la Ulterior contra los astures, a manos de Publio Carisio. En el 26 a. C., Augusto toma el mando de la guerra en persona y establece su base de operaciones junto a Segisama hasta el año siguiente, cuando enferma y se retira a Tarraco para restablecerse, dejando el mando de la guerra contra los cántabros a Cayo Antistio, quien dirige la toma de Bergidum y el sitio del Mons Vindius, donde tiene lugar la finalización de la resistencia cántabra. Por otra parte, tras la retirada del princeps, Publio Carisio se hace cargo del mando de las operaciones militares contra los astures, y, ya bajo sus órdenes, se ataca Lancia en el 25 a. C.

En un breve lapso de tiempo comienzan a producirse nuevos estallidos de sublevación contra Carisio -en 24, 23 y 22 a. C.-. Los cántabros sufren una nueva derrota en el Mons Medullius, a la que sucede un período de relativa paz hasta el 19 a. C., en que resurgen las sublevaciones. Como medida extrema, interviene M. V. Agripa, acompañado de la legio IIII Macedonica, para pacificar definitivamente el territorio. Es de suponer que tuvieran lugar expediciones punitivas, que incluían la destrucción y arrasamiento de castros, así como el traslado de la población a las llanuras.

En la posguerra tiene lugar el amplio programa de fundaciones cívico-militares proyectadas por el emperador, entre las que destacan Augusta Emerita, donde se asientan los veteranos de la $V$ Alaudae y la $x$ Gemina, y Caesar Augusta, fundada por veteranos de la IIII Macedonica, la VI Victrix y la X Gemina. 
Desafortunadamente, son aún escasos los hallazgos que confirmen las fuentes clásicas, precisamente por la escasez de investigaciones sistemáticas en estos asentamientos militares. De manera reiterada, se infiere la identificación de yacimientos por su localización en itinerarios o descripciones someras en algunos textos clásicos y medievales, dato insuficiente para una tipificación veraz. Una gran mayoría de los campamentos localizados permanecen sin un trabajo sistemático, y es habitual la carencia de categorización cronológica o de su naturaleza. Por el contrario, suele conocerse una descripción pormenorizada de su superficie, tamaño, morfología y tipología, por la facilidad de adquisición de estos datos. Actualmente los más aceptados como seguros corresponden a asentamientos estables cuyo topónimo, además, ha perdurado a lo largo del tiempo.

En lo que concierne a asedios, posiblemente el mejor documentado es el de La Loma, en Palencia (Peralta, 2015). Otros hallazgos, como el complejo de La Muela-Mesa de Quintanilla (Bohigas et al., 2015), el de Castillejo (Peralta et al., 2011), el de Santa Marina en Valdeolea (Fernández y Bolado, 2011) o los asociados a la toma de la Espina del Gallego (Peralta, 2000), apuntan a intensos movimientos en los cordales montañosos, con violentos asaltos a castros y escaramuzas hasta en retaguardia (Peralta, 2001). A diferencia de lo que sucede en este sector, para otros escenarios vinculados a las guerras cántabras se dispone de dataciones de $\mathrm{C}^{14}$, como, por ejemplo, A Granda das Xarras y A Recacha (Orejas et al., 2015), El Outeiro en Taramundi (Menéndez y Sánchez, 2018: 291) o el complejo castramental de La Carisa (Camino, 2015). Recientemente la datación radiocarbónica del campamento de A Penaparda arrojaba fechas del s. XII en el agger (Costa et al., 2020) que no permiten aclarar aún la incógnita de su datación.

Capítulo aparte es el de las bases legionarias permanentes, establecidas una vez finalizada la guerra, y perfectamente datadas a través de los contextos materiales, como sucede en León (Morillo y García Marcos, 2006; Morillo, 2012), en Herrera (Morillo et al., 2006) o en Astorga (Morillo, 2006; Vidal y González, 2018).

Ediciones Universidad de Salamanca / 요요
Terminada la guerra, el nuevo territorio anexionado por Roma al pie de la Cordillera pasó a formar parte de la provincia Tarraconensis. Se produjo entonces una reorganización de todos los efectivos militares que habían sido empleados en la guerra y se creó un exercitus Hispanicus constituido en un primer momento, según informa Estrabón (III, 4, 20 ), por tres legiones, cuya presencia se prolonga a lo largo del período julioclaudio. Hoy no cabe duda de que las legiones VI Victrix y $X$ Gemina estuvieron asentadas en territorio astur, mientras la IIII Macedonica se estableció en el límite meridional de Cantabria (Morillo, 2002: 77-79). Acantonada en Herrera de Pisuerga, en territorio turmogo, y cerca del límite con los cántabros, la legio IIII Macedonica desempeñó durante seis décadas un papel fundamental para la pacificación y el control del nuevo territorio incorporado (Morillo, 2000; Morillo et al., 2006). Herrera se suele identificar con Pisoraca, ciudad perteneciente a los turmogos que es mencionada por Ptolomeo (II, 6, 51) como Sisaraca y como Pistoraca en el Ravennate $(318,13)$. Solo testimonios epigráficos se refieren a ella con el que parece ser su nombre correcto, Pisoraca, el mismo que recibe el río Pisuerga, cuyo nombre deriva precisamente del asentamiento indígena. El registro documental de Herrera parece descartar que la ciudad romana de Pisoraca fuera un núcleo urbano surgido de las cannabae legionarias tras la partida de la IIII $M a-$ cedonica, aunque se encontraría en sus cercanías (Morillo, 2000: 616). Las estratigrafías de Herrera confirman su ocupación entre el 20/15 a. C. y el 39 d. C., año en que la legio IIII Macedonica parte hacia Mogontiacum, actual Mainz. Herrera hubo de ser capital de todo el distrito militar correspondiente al antiguo territorio cántabro.

La articulación del territorio tras la conquista implicó una presencia militar activa, donde hubo de ser necesaria la implantación de puntos de control y vigilancia en relación a vías de comunicación. Precisamente sobre la red de arterias viarias hubo de surgir toda una red de acuartelamientos secundarios, además de las guarniciones establecidas sobre algunos oppida. Asentamientos como Monte Cildá, Peña Amaya, Los Majuelos -en Olmos de Ojeda- o 
La Poza pudieron formar parte de este dispositivo (Morillo, 2008: 148-149).

En el 39 d. C. se produce la marcha de la legio IIII Macedonica de Herrera de Pisuerga, implicando el desmantelamiento de buena parte del dispositivo militar presente en esta región septentrional de las actuales provincias de Burgos y Palencia. Sin embargo, los innegables condicionantes geoestratégicos de Herrera, controlando la principal vía de comunicación entre la Meseta y el Cantábrico, contribuyeron, sin duda, a la perduración militar del asentamiento a través de distintas unidades auxiliares -el ala Parthorum y la cohors I Gallica-, al menos hasta finales del s. I d. C. (Morillo, 2008: 150-155).

\section{Metodología empleada}

El empleo de técnicas de teledetección no intrusivas en el ámbito de la Arqueología Militar Romana es una herramienta recurrente en los últimos años, dada la accesibilidad actual y gratuidad de los datos espaciales y cartográficos en diferentes plataformas web. Como mencionábamos arriba, el proyecto tuvo como principal propósito mejorar el nivel de información existente acerca de toda una serie de asentamientos, centrándose en aquellos lugares potencialmente relacionables con las guerras asturcántabras, lo que supuso un proceso de revisión y documentación de 86 yacimientos en primera instancia y 156 al finalizar el trabajo. Esta recopilación documental incluía datos de tipo cartográfico y ortofotográfico, resultados de prospecciones pedestres y aéreas, revisión de colecciones museísticas, bibliográficas y otros.

El apartado de documentación conjugó diferentes sistemas de prospección para obtención de datos, volcándose, mediante protocolos informáticos genéricos, en un SIG -Sistema de Información Geográfica-.

De manera preliminar tuvo lugar la realización de una batería de figuras de cada yacimiento ${ }^{4}$ que

4 Dada la amplitud espacial del trabajo, se decidió restringir el área de análisis en torno a cada yacimiento catalogado. Concretamente, se delimitó un área en forma de incluyese todas las ortofotografías históricas obtenidas a través del servicio web del Instituto Geográfico Nacional -IGN- y de la Fototeca del Centro Nacional de Información Geográfica ${ }^{5}$-CNIG-, así como el examen de las mismas. La revisión de imagen aérea se muestra como uno de los métodos más útiles de prospección en arqueología militar desde hace décadas (Loewinsohn, 1965; Sánchez Palencia, 1986; Peralta, 2000). Esto incluyó la revisión del Vuelo Americano Serie A (1945-1946), el Vuelo Americano Serie в (1956-1957), el Vuelo Interministerial (1973-1986), el Vuelo de SIGPAC (1997-2003) y los vuelos del Plan Nacional de Ortofotografía Aérea -PNOA- disponibles en cada caso específico. Así mismo, en casos concretos se decidió realizar un examen de ortofotografías de los servicios Google Earth, Bing Maps y HERE WeGo.

Dentro de esta generación de planimetrías se incluyó la elaboración de Modelos Digitales del Terreno $-\mathrm{MDT}^{6}{ }^{6} \mathrm{y}$ de planos de curvas de nivel con

cuadrado equilátero, cuyo lado tendría una longitud (aproximada) que equivaldría al doble del eje mayor del campamento en cuestión.

5 https://fototeca.cnig.es/; acceso 5/07/2020.

6 Para la elaboración de los Modelos Digitales del Terreno -MDT- se filtraron los puntos LiDAR a utilizar, empleando por norma general únicamente aquellos clasificados como suelo o Ground. En ocasiones, debido a las inevitables deficiencias de los datos base, fue necesario reclasificar o retocar parte de la nube de puntos del IGN, bien para filtrar elementos no deseados -vegetación, construcciones, etc.-, o bien para evitar problemas de error por superposición, causados a menudo por el contacto entre diferentes pasadas o diferentes vuelos de toma de datos. Una vez resuelto cualquier problema existente en la nube de puntos LiDAR, se utilizó para la creación del modelo un algoritmo de Binning por valor promedio, con un tamaño de celda calculado automáticamente para adaptarse de manera óptima al espaciado de puntos existente en dicha área. Si bien este sistema suaviza algo más el terreno que un método tipo Triangulation, se consideró que, en la práctica, la diferencia entre ambos era escasa a la hora de identificar elementos de interés, mientras que el aspecto general de la imagen mejoraba notablemente de este modo. En casos particulares resultó necesario utilizar interpolaciones de datos mediante los sistemas Kriging o $I D W$, con el fin de rellenar de un modo adecuado zonas en las que era muy escaso el número de puntos Lidar tipo suelo. Eso ocurría, principalmente, en áreas con una enorme 
espaciado de a 0,5 y $0,2 \mathrm{~m}$, elaborados en ambos casos a partir de las nubes de puntos LiDAR -Laser Imaging, Detection and Ranging- del IGN. Para ello se utilizó, como base, la primera cobertura realizada por este Instituto, al ser la única disponible a fecha del trabajo, y que cuenta con una resolución media de $0,5 \mathrm{p} / \mathrm{m}^{2}$ en esta región. Su utilidad para la detección de sutiles cambios en el terreno es clara, llegando a convertirse en indispensable para la correcta resolución de algunos espacios (Chase et al., 2017: 89).

La realización de vuelos durante las prospecciones -haciendo uso de 3 drones de diferentes características a fin de obtener resultados dispares a comparar: Xiaomi MiDrone 4K, Mavic 2 Pro $4 \mathrm{~K}$ e Inspire 1 dotado de cámara Zenmusex $5 \mathrm{R}$ - permitió, además de grabación de vídeos y fotografías oblicuas en formato RAW, la generación de fotogrametrías y ortofotografías para ser manipuladas con posterioridad. Las instantáneas obtenidas fueron sometidas en casos concretos a diferentes filtros, resultando especialmente útiles, a pesar de no haber sido específicamente concebidos para ello, el Dstretch, pensado en primera instancia para una mejor adquisición de imágenes en arte rupestre, el filtro viveza de Nik-Collection o el falso infrarrojo.

Finalmente, tuvo lugar el dibujo, en caso viable, de plantas con la interpretación arqueológica, utilizando como base los datos examinados previamente -irregularidades en la superficie, alteraciones de cota, crecimiento diferencial en los cultivos-, apoyada siempre en la documentación y bibliografía ya existentes, así como en el trabajo de campo.

densidad de vegetación, en las que el láser aerotransportado tiene dificultades para alcanzar el terreno geológico.

Respecto a la representación gráfica de los MDTs en sus correspondientes láminas, se utilizó en todos los casos una escala única de colores que fue creada ex profeso para este proyecto. Por otro lado, todo MDT generado fue incluido con y sin sombreado. Para este segundo caso, se empleó una exageración vertical de $30-\mathrm{x} 3-$, una oscuridad de sombra de 70 -sobre 255-, una luz ambiente de 0 y un reflejo por luz directa de 0 , mientras que los valores de altitud y acimut variaron para cada caso particular, ajustándolos manualmente con el fin de resaltar cualquier elemento de interés tanto como fuese posible.
A pesar de las citadas limitaciones, durante el proceso de realización del proyecto tuvieron lugar una serie de descubrimientos iniciales que parecían corresponderse con posibles recintos campamentales romanos. Fue el caso de los yacimientos de Herrera, extraordinariamente cercanos al núcleo de análisis; o del cerro Castarreño, por idéntica circunstancia. Mayoritariamente, los hallazgos fueron realizados a través de ortofotografías, especialmente en aquellas obtenidas en períodos de crecimiento diferencial vegetativo o en momentos de acumulación de humedad o nieve. Resultó de extraordinaria ayuda contar con las planimetrías levantadas por Moreno $(2000,2011)$ de la articulación viaria en la Meseta. Obviamente, los antiguos ramales viarios conocidos resultan de especial interés, así como la red fluvial que señala posibles rutas de paso, en ocasiones mostrando con claridad campamentos situados a intervalos regulares.

No incidimos en el uso de datos LiDAR por cuanto en este caso concreto no se ha demostrado especialmente útil, al encontrarnos ante terrenos de explotación agrícola continuada, en los que la maquinaría ha desdibujado las anomalías y desniveles existentes en el terreno.

\section{Catálogo de yacimientos militares (Fig. 1)}

Es evidente la discusión científica existente entre los investigadores españoles en relación a la terminología adecuada para la definición del fenómeno militar. Resulta compleja la comprensión de algunas publicaciones recientes precisamente por la falta de coincidencia. Aun así, se han realizado esfuerzos notables para centrar este tipo de cuestiones ${ }^{7}$.

En la actualidad existe la identificación casi constante de cualquier hallazgo descrito como recinto temporal, campamento de campaña o castra aestiva. Ello se debe a la presencia de fortificaciones en materiales perecederos y carencia de estructuras y materiales. Por desgracia, el estado inicial

$7 \mathrm{Al}$ respecto, pueden consultarse abundantes referencias: Peralta, 2002; Mora, 2007; Ble, 2012; Quesada, 2014; Morillo et al., 2020. 


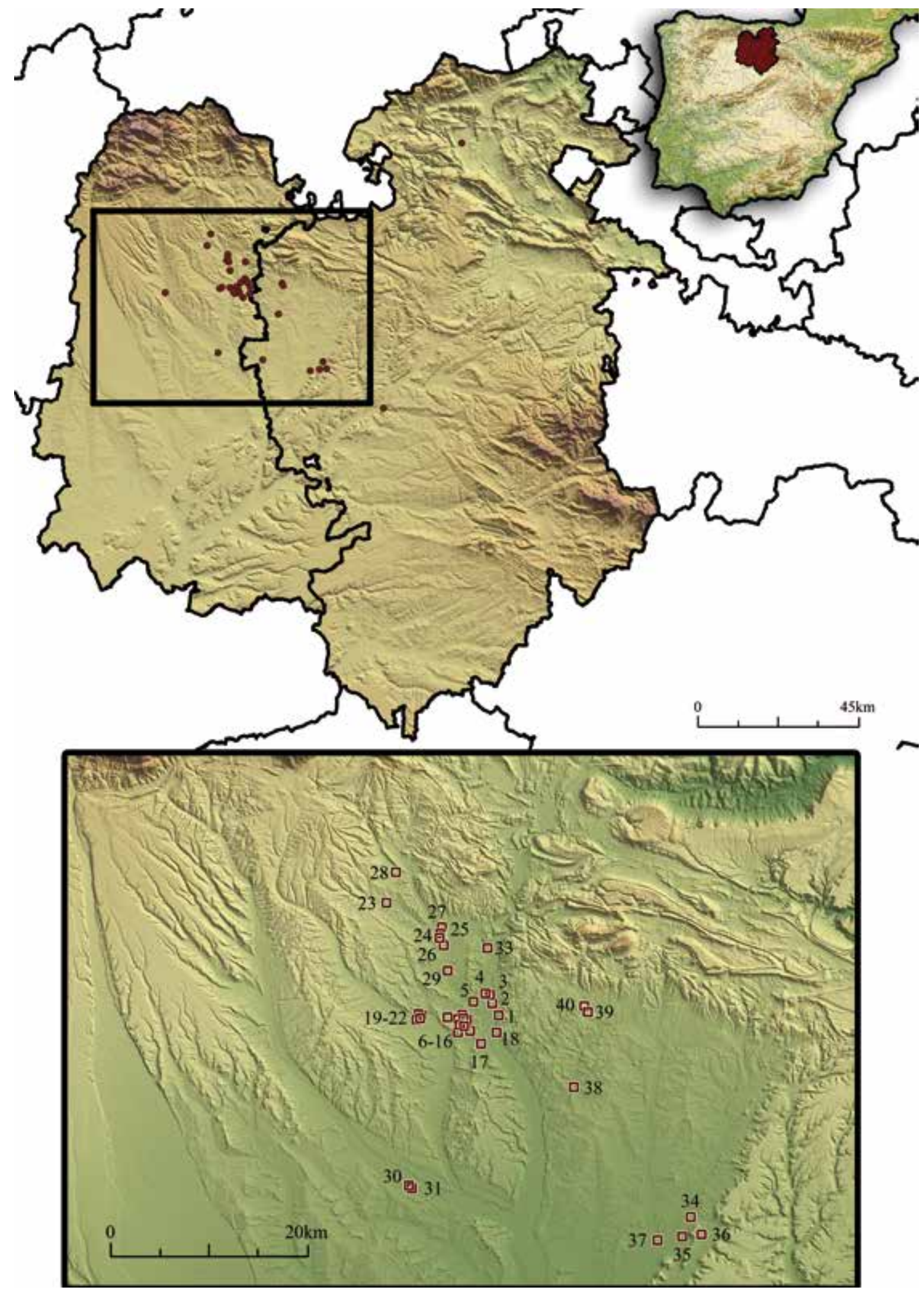

Fig. 1. Localización, sobre las actuales provincias de Burgos y Palencia, de los nuevos yacimientos mencionados en el texto. 
y/o parcial de la investigación, con escasas excavaciones en este tipo de establecimientos, no permite asegurar su naturaleza temporal o de campaña en la mayor parte de los casos, por lo que hablamos de identificaciones apriorísticas como 'campamentos de batalla o de conquista'. La indefinición cronológica, igualmente, lleva a una identificación preliminar dentro del período de la conquista, aún a falta de prospecciones o excavaciones que confirmen tal punto (Morillo et al., 2020: 49-50).

Probablemente, el desarrollo de intervenciones sistemáticas permitirá avanzar en el reconocimiento de los diferentes tipos de recintos y su caracterización y, mediante la diferenciación de su registro -materiales y estructuras-, definir tipos de asentamiento más precisos, tal y como sucede en otros países, donde la investigación en torno a establecimientos temporales y en materiales perecederos está más desarrollada (Jones, 2011, 2012). Ello está íntimamente relacionado con el problema cronológico ya reseńado, en que cualquier recinto hallado a través de la fotointerpretación es inmediatamente asimilado con el período entre 29 y 19 a. C. Precisamente por esta circunstancia, nos referiremos en todo momento a estos espacios como campamentos, término más neutro, sin categorizarlos a priori. Las explicaciones históricas en estos casos no dejan de ser meras hipótesis, fundamentadas en datos toponímicos y fuentes históricas y geográficas.

El desarrollo del trabajo aportó numerosos nuevos emplazamientos (Fig. 2), de los cuales señalamos aquí tan solo algunos, aquellos que resultan especialmente interesantes por la posible interpretación que se deriva de sus características y emplazamiento.

\subsection{Complejo campamental de Herrera de Pisuerga}

Alrededor de Herrera de Pisuerga se localizan cerca de una veintena de nuevos recintos campamentales y una decena de trazas dudosas sobre el terreno (Figs. 2 y 3, n. ${ }^{\text {os }} 1$ 1-18). Categorizar dichos espacios es cuando menos complejo, dado el uso continuado del territorio como tierras de labranza. Su localización geoespacial y la propia morfología de los recintos parece indicar, así mismo, diferentes usos. De $\mathrm{E}$ a $\mathrm{O}$, encontramos Valdehorno, en un emplazamiento geoestratégico idóneo, un alto que domina todo el valle del Pisuerga y posee una de las vistas más privilegiadas del entorno, estando en línea visual directa con Peńa Amaya. El cerro, de laderas tendidas y fácilmente accesibles, destaca sobre el resto del paisaje circundante, habiéndose localizado una de las puertas en clavícula en el punto más septentrional del mismo. Ya en la zona de vega, Las Huelgas, identificado años atrás (Didierjean et al., 2014); Camino Hondo, y Barrialba, al $\mathrm{N}$ de Herrera, y, dentro del núcleo urbano, Los Renedos, al parecer ya constatado, pero nunca publicado, por el recientemente desaparecido E. Illarregui.

$\mathrm{Al}$ so de la actual población se reconoce una docena de recintos de diferentes dimensiones y orientación, todos también de planta rectangular a excepción del de Calderón. En todos ellos se identifican puertas simples y esquinas en forma de naipe. La Cantera, La Culebra, Rasillas 1 a 4, Valmayor -con dudas-, Medias Navas, Matabueyes, Calderón, Pedernales o, ya más alejado, Peralejos, presentan plantas regulares, aunque no siempre de lados paralelos, y es significativa la absoluta ausencia de materiales en superficie. Finalmente, hay hallazgos más dudosos, como los Valdemiranda, aparentemente una torre cuadrangular o similar.

Todos ellos se encuentran a distancias entre 1,5 y $3,5 \mathrm{~km}$ del núcleo de Herrera (Fig. 3), ubicado sobre los antiguos castra de la legio IIII Macedonica y los fuertes posteriores para unidades auxiliares - el ala Parthorum y la cohors I Gallica-. Esta circunstancia, sumada a la inexistencia de trazas completas en muchos de ellos, nos lleva a pensar en un campo táctico de entrenamiento de las tropas acantonadas en dichos recintos.

\subsection{Complejo campamental de Páramo de Boedo}

A una distancia a pie de aproximadamente una hora a paso ligero de Herrera se encuentra el complejo de Páramo de Boedo, compuesto por al menos 4 recintos, de plantas rectangulares con esquinas de naipe (Figs. 2 y 3, n. ${ }^{\text {os }} 19-22$ ). El único que conserva su planta completa, Vega de Arriba 1, presenta una

Zephyrus, LXXXVI, julio-diciembre 2020, 143-164 


\begin{tabular}{|c|c|c|c|c|c|}
\hline Nombre y localización & $\begin{array}{l}\text { Perímetro } \\
(\mathrm{m})\end{array}$ & $\begin{array}{l}\text { ÁrEA } \\
\text { (ha) }\end{array}$ & $\begin{array}{l}\text { EJE LONGITU- } \\
\text { DINAL } \\
(\mathrm{m})\end{array}$ & $\begin{array}{c}\text { EJE } \\
\text { TRANSVERSAL } \\
(\mathrm{m})\end{array}$ & $\begin{array}{c}\text { Altitud } \\
\text { MEDIA } \\
(\mathrm{m})\end{array}$ \\
\hline 1. Valdehorno, Herrera de Pisuerga (Palencia) & _- & _- & $>187$ & $\approx 168$ & $\approx 871$ \\
\hline 2. Las Huelgas, Herrera de Pisuerga (Palencia) & - & - & $\approx 482$ & $>282$ & $\approx 836$ \\
\hline 3. Camino Hondo, Herrera de Pisuerga (Palencia) & _- & - & $>250$ & $>79$ & $\approx 836$ \\
\hline 4. Barrialba, Herrera de Pisuerga (Palencia) & $\approx 1025$ & $\approx 6,89$ & $\approx 296$ & $\approx 235$ & $\approx 837$ \\
\hline 5. Los Renedos, Herrera de Pisuerga (Palencia) & - & $\ldots$ & $>234$ & $>124$ & $\approx 854$ \\
\hline 6. La Cantera, Páramo de Boedo (Palencia) & _- & _- & $>141$ & $>42$ & $\approx 863$ \\
\hline 7. La Culebra, Páramo de Boedo (Palencia) & _- & _- & $\approx 182$ & $>97$ & $\approx 858$ \\
\hline 8. Rasillas 1, Herrera de Pisuerga (Palencia) & - & - & $>131$ & $\approx 140$ & $\approx 860$ \\
\hline 9. Rasillas 2, Herrera de Pisuerga (Palencia) & - & - & $>190$ & $>65$ & $\approx 862$ \\
\hline 10. Rasillas 3, Herrera de Pisuerga (Palencia) & _ & _ & $\approx 258$ & $>117$ & $\approx 864$ \\
\hline 11. Rasillas 4, Herrera de Pisuerga (Palencia) & _- & _- & $>29$ & $\approx 80$ & $\approx 858$ \\
\hline 12. Valmayor, Calahorra de Boedo (Palencia) & - & - & $>128$ & - & $\approx 867$ \\
\hline 13. Medias Navas, Herrera de Pisuerga (Palencia) & $\approx 109$ & $\approx 0,08$ & $\approx 32$ & $\approx 26$ & $\approx 857$ \\
\hline 14. Matabueyes, Calahorra de Boedo (Palencia) & - & - & $>55$ & $>51$ & $\approx 860$ \\
\hline 15. Calderón, Herrera de Pisuerga (Palencia) & $\approx 177$ & $\approx 0,23$ & $\approx 55$ & $\approx 46$ & $\approx 854$ \\
\hline 16. Pedernales, Calahorra de Boedo (Palencia) & $\approx 585$ & $\approx 2,08$ & $\approx 180$ & $\approx 116$ & $\approx 911$ \\
\hline 17. Peralejos, Herrera de Pisuerga (Palencia) & $\approx 497$ & $\approx 1,59$ & $\approx 156$ & $\approx 84$ & $\approx 839$ \\
\hline 18. Valdemiranda, Herrera de Pisuerga (Palencia) & $\approx 147$ & $\approx 0,14$ & $\approx 46$ & $\approx 37$ & $\approx 826$ \\
\hline 19. Vega de Arriba 1, Páramo de Boedo (Palencia) & $\approx 743$ & $\approx 3,53$ & $\approx 214$ & $\approx 168$ & $\approx 872$ \\
\hline 20. Vega de Arriba 2, Páramo de Boedo (Palencia) & - & - & $>231$ & - & $\approx 873$ \\
\hline 21. Vega de Arriba 3, Páramo de Boedo (Palencia) & _- & _ & $>100$ & _- & $\approx 875$ \\
\hline 22. La Vega, Páramo de Boedo (Palencia) & - & - & $>43$ & - & $\approx 873$ \\
\hline 23. La Fuentecilla, Micieces de Ojeda (Palencia) & $\approx 1054$ & $\approx 7,38$ & $\approx 340$ & $\approx 243$ & $\approx 925$ \\
\hline 24. La Calzada, La Vid de Ojeda (Palencia) & $\approx 820$ & $\approx 4,36$ & $\approx 240$ & $\approx 183$ & $\approx 872$ \\
\hline 25. Fresnillo, La Vid de Ojeda (Palencia) & - & - & $>118$ & $>67$ & $\approx 875$ \\
\hline 26. El Témpano, La Vid de Ojeda (Palencia) & _- & _- & $>181$ & $\approx 170$ & $\approx 869$ \\
\hline 27. La Quebrantada, La Vid de Ojeda (Palencia) & - & _- & $>72$ & - & $\approx 882$ \\
\hline 28. Los Majuelos, Olmos de Ojeda (Palencia) & $\approx 689$ & $\approx 3,17$ & $\approx 197$ & $\approx 165$ & $\approx 929$ \\
\hline 29. Los Aviles, Herrera de Pisuerga (Palencia) & $\approx 783$ & $\approx 3,89$ & $\approx 238$ & $\approx 161$ & $\approx 854$ \\
\hline 30. Carrecampo, Abia de las Torres (Palencia) & $\approx 1010$ & $\approx 6,09$ & $\approx 327$ & $\approx 186$ & $\approx 814$ \\
\hline 31. El Cordero, Abia de las Torres (Palencia) & - & - & $>202$ & $>188$ & $\approx 814$ \\
\hline 32. Arenillejas, Buenavista de Valdavia (Palencia) & $\approx 123,31$ & $\approx 0,09$ & $\approx 32$ & $\approx 30$ & $\approx 887$ \\
\hline 33. La Charcona, Alar del Rey (Palencia) & + & - & $\approx 262$ & $>102$ & $\approx 860$ \\
\hline 34. Carrecastro, Sasamón (Burgos) & $\approx 1065$ & $\approx 7,38$ & $\approx 313$ & $\approx 236$ & $\approx 804$ \\
\hline 35. Andinales, Villasandino (Burgos) & $\approx 664$ & $\approx 2,84$ & $\approx 202$ & $\approx 145$ & $\approx 803$ \\
\hline 36. Carrecastrillo, Sasamón (Burgos) & $\approx 681$ & $\approx 2,50$ & $\approx 197$ & $\approx 144$ & $\approx 833$ \\
\hline 37. Las Cañadas, Villasandino (Burgos) & - & - & $\approx 320$ & $>62$ & $\approx 791$ \\
\hline 37. Calzada, Sotresgudo (Burgos) & $\approx 393$ & $\approx 1,02$ & $\approx 113$ & $\approx 92$ & $\approx 829$ \\
\hline 39. Tortolondro, Sotresgudo (Burgos) & $>1894$ & $>21,88$ & $\approx 544$ & $>415$ & $\approx 900$ \\
\hline 40. Matimocho, Sotresgudo (Burgos) & $\approx 1535$ & $\approx 13,14$ & $\approx 486$ & $\approx 339$ & $\approx 894$ \\
\hline
\end{tabular}

FIG. 2. Dimensiones de los recintos militares referidos en el texto. 
ratio de 2:3, tertiata, como indicase Higinio. De los demás tan solo puede recuperarse por ortofotografía alguno de sus laterales o esquinas. Los recintos se localizan junto al río Boedo.

\subsection{Complejo campamental de Ribera del Burejo}

A lo largo de la ribera del Burejo se reconocen diferentes yacimientos (Fig. 2, no. ${ }^{\text {os }} 23-29$ ) -La Fuentecilla, en Micieces; La Calzada; Fresnillo; El Témpano o La Quebrantada, en La Vid de Ojeda; Los Majuelos, en Olmos, y Los Aviles, en Villabermudo, algunos de los cuales ya han recibido atención previa por parte de otros investigadores ${ }^{8}$. Sin extendernos en demasía, puesto que se encuentran en estudio, cabe reseñar que estos recintos en general presentan unas dimensiones más notables que los referidos en el entorno so de Herrera, además de presentar superposiciones de establecimiento -Los Majuelos- y defensas más complejas - titula en Villabermudo, puertas en clavícula en Micieces-. En todos ellos se documenta material en superficie, siendo destacable la presencia de cerámica datada en época tardoaugústea al menos en tres de ellos. Ello nos permite inferir un establecimiento al menos en un momento inmediatamente posterior a la conquista, tal vez incluso anterior. Los establecimientos se localizan junto al río Burejo, a una distancia nunca inferior de $250 \mathrm{~m}$ respecto del cauce fluvial (Fig. 4).

\subsection{Circumvallatio del Monte Castarreño, en Sasamón, Burgos ${ }^{9}$}

El análisis del área segisamonense se realizó dada la noticia de evidencias a partir de la fotografía aérea

8 Es el caso de Los Majuelos y Los Aviles, parte de cuyos materiales ya fueron estudiados por Nuño (1990) y Fernández-Ibáńez (2007) y alguno está recogido ya por Morillo (2008).

9 Recientemente, García Sánchez y Costa (2020) han publicado un trabajo sobre análisis geoespacial y de teledetección de Segisamo, si bien en ningún tramo de ese artículo se llega a hacer referencia a la identificación de los restos que aquí presentamos. en la zona de Carrecastro (Didierjean et al., 2014), consistentes en dos líneas paralelas que discurrían en dirección E-W a partir del recinto campamental de Carrecastro (Fig. 2, n. ${ }^{\text {s }}$ 34-37). La morfología y las dimensiones de estas trazas, tanto desde satélite como en campo, parecían indicar su falta de correspondencia con viario romano alguno ${ }^{10}$. La continuidad de estos restos se prolonga en derredor del cerro Castarreño, conformando dos cercos aparentemente estancos con posiciones campamentales jalonadas cada cierto espacio. Interpretamos, por tanto, todo este perímetro como una circumvallatio acompañada de contravallatio, un claro recurso de asedio para la toma del oppidum (Fig. 6). Aparentemente, se trata de un complejo dotado de fossa duplex a tenor de las evidencias percibidas tanto en superficie como en ortofotografía, con unas medidas de $2 \mathrm{~m}$ de ancho cada una de estas unidades negativas y una anchura total superior a los $9.5 \mathrm{~m}$ -medidas efectuadas sobre el terreno al se del campamento de Carrecastro-. En el extremo oriental del perímetro fortificado, este desaparece, posiblemente por ser innecesario, dada la existencia de un curso hídrico -arroyo de La Vega o de Mediovino- que sigue la deriva de los fosos de un modo casi exacto.

A esta fortificación, a la que sin duda acompañaría algún agger, se suma la existencia de otras evidencias: los ya conocidos recintos de Carrecastro y $\mathrm{La}$ Veguilla; el nuevo recinto de Andinales, de planta casi rectangular y con laterales ligeramente desviados en los ejes norte sur, conformando una suerte de trapecio (Fig. 5), emplazado sobre un leve altozano al oeste del cerro Castarreño; los restos visibles en imagen aérea de los recintos de Santa Eulalia y Carrecastrillo, o los dos posibles recintos en el Collado Carrancha, al suroeste del cerro. Estos últimos resultan un baluarte de control sobre el único paso en la zona, que pervive hasta la actualidad, en la zona de Hoyo Campana (Fig. 6).

Aproximadamente a $2,5 \mathrm{~km}$ al o aparecen las trazas de otro posible recinto, Las Cañadas, en Villasandino, nuevamente de planta rectangular y con una posible puerta conservada al s (Fig. 5).

10 Nos gustaría agradecer su inestimable ayuda a I. Moreno Gallo en este punto. 

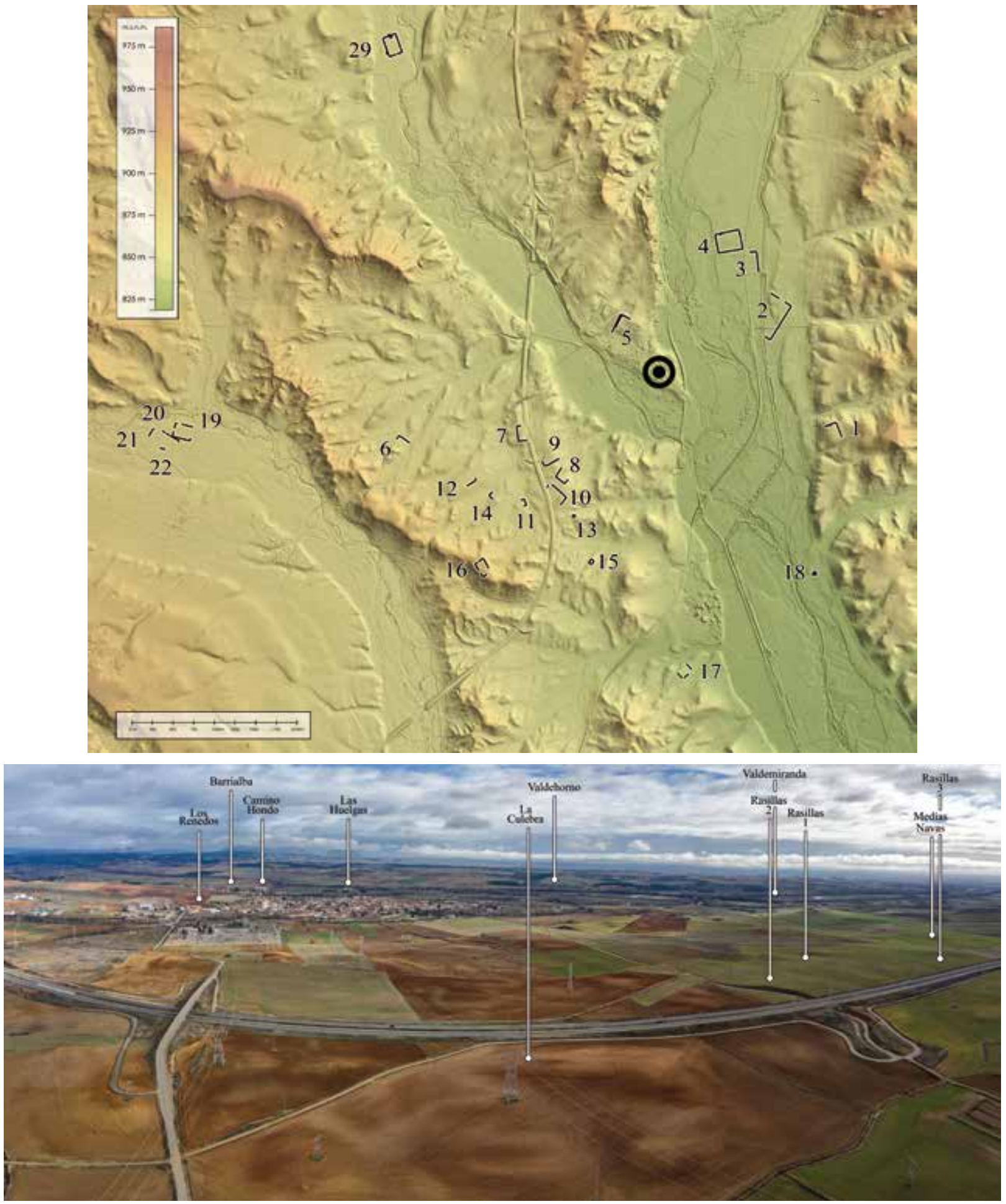

FIG. 3. Arriba: Localización sobre modelo digital del terreno de los nuevos campamentos en el entorno de Herrera; la numeración se corresponde con la de la Fig. 2. Abajo: imagen aérea de parte de los recintos de Herrera (Z. Perrino, 2019); en primer término, visible por diferencia colorimétrica del suelo, el recinto de La Culebra. 
154 E. Martín Hernández, A. Martínez Velasco, D. Díaz Alonso et al. / Castrametación romana en la Meseta Norte...
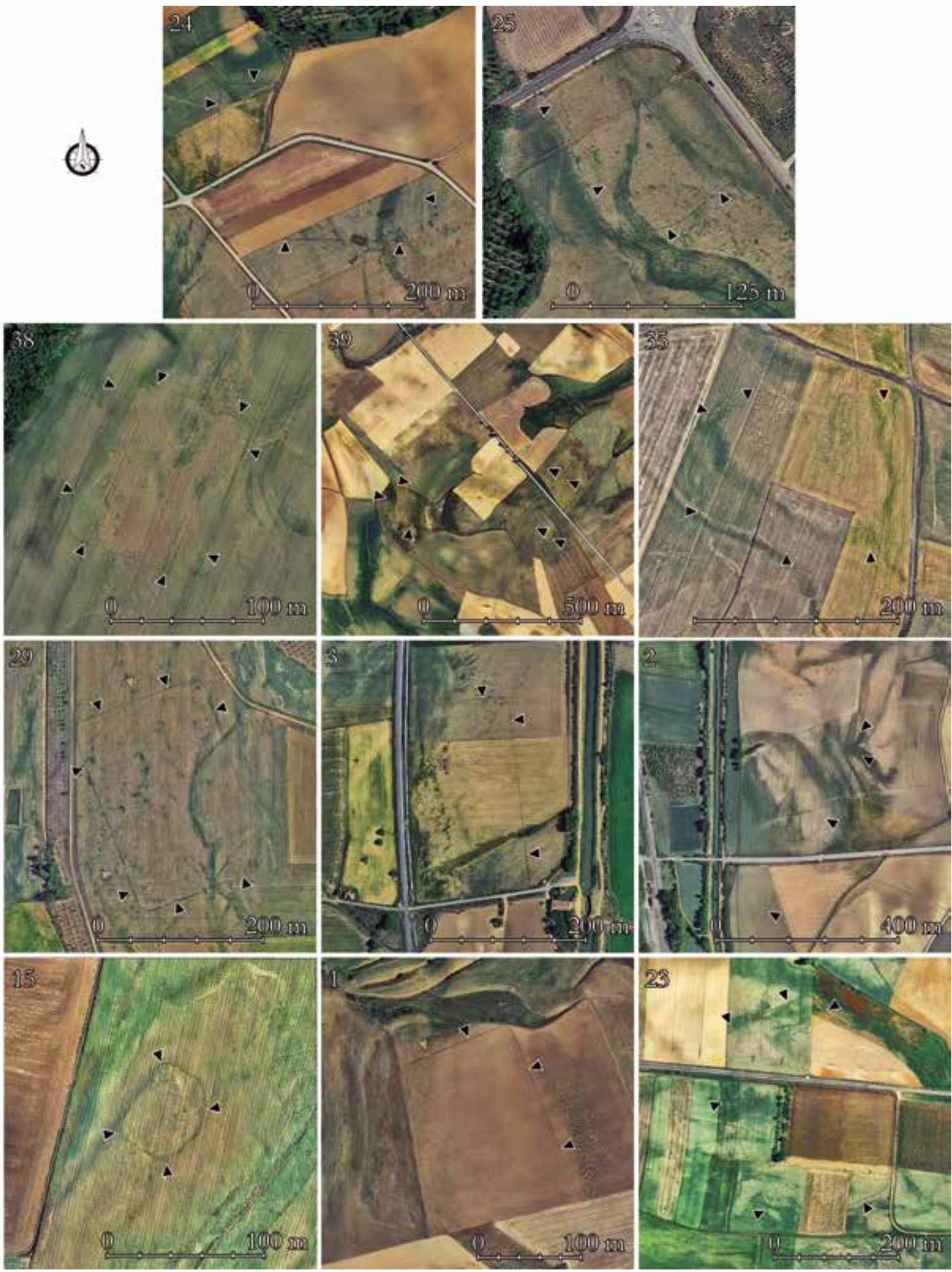

Fig. 4. Ortofotografía de algunos nuevos recintos; la numeración se corresponde con la de la Fig. 2. 


\subsection{Campamentos de Tortolondro/Matimocho y Calzada (Sotresgudo, Burgos)}

Entre las áreas de Herrera y Sasamón se localizan al menos tres campamentos más, de características bastante diferentes entre sí (Fig. 2, n. ${ }^{\text {os }} 38-40$ ). El recinto de Calzada se emplaza sobre un suave altozano y, respondiendo a su topónimo, junto a la vía ya reconocida por Moreno ${ }^{11}$, de planta rectangular y reducidas dimensiones; mientras que Tortolondro cuadriplica estas medidas, con un eje longitudinal de unos $550 \mathrm{~m}$ y un posible recinto cercano de planta irregular, Matimocho, similar a otros ya documentados en el norte peninsular, como Valbona, en el Mouro, o los de Las Cruces (Martín Hernández, 2015). Tortolondro, de igual manera que sucede en Los Majuelos, presenta una superposición de estructuras que parecen indicar o bien un establecimiento prolongado o la reiteración de la ocupación del mismo espacio en diferentes momentos. La posición de este campamento es excepcional, en una ligera elevación sobre una amplia llanura, desde donde se controlan los asentamientos de cerro Castrillo, del Alto de la Mesa y Las Castilleras, teniendo en perspectiva la gran mole de Peña Amaya.

\subsection{Campamentos de Abia de las Torres}

Finalmente, y sin entrar en consideración del carácter militar de algunos materiales recuperados en el yacimiento de Dessobriga, que se tratarán en otras publicaciones, existe en Abia de las Torres un conjunto de al menos dos campamentos, Carrecampo y el Cordero, superpuestos el uno al otro, pero ambos de forma rectangular con esquinas redondeadas (Fig. 2, n. ${ }^{\text {s }} 30-31$ ).

\section{Análisis arqueológico de las evidencias documentadas}

A pesar de que la información disponible es todavía limitada, debido a la ausencia de la necesaria

11 https://viasromanas.net/; acceso 4/07/2020. intervención arqueológica sobre el terreno, podemos apuntar algunas consideraciones. Así, por ejemplo, uno de los conjuntos de campamentos más interesantes es el que se localiza en torno a Herrera de Pisuerga, que viene a completar el localizado previamente en el paraje de Las Huelgas (Didierjean et al., 2014: 164). Se detectan dos concentraciones muy claras, una hacia el E, en torno al río Pisuerga, y otra hacia el so. Los recintos presentan en común su trazado ortogonal, de planta presumiblemente rectangular, con esquinas redondeadas y algunos accesos regulados mediante puertas en clavícula interna, en aquellos casos que se han podido identificar.

Los datos de que disponemos ahora para la caracterización de estos campamentos resultan limitados, pero es pertinente realizar algunas observaciones atendiendo a sus características, el emplazamiento elegido y su posible cronología, ya que, aunque existe una cierta variedad, hay características comunes reseñables. En ese sentido, el campamento de Valdehorno, incompleto, pero con un eje de 168 $\mathrm{m}$, una puerta en clavícula y un emplazamiento dominante sobre el Pisuerga, podría corresponder a un campamento de jornada. Los numerosos restos campamentales situados en el so, en cambio, de menor tamaño en general, en una zona más llana y algo apartados de la principal vía de comunicación, bien pudieran responder a ejercicios de entrenamiento de las tropas romanas acantonadas en Herrera.

Finalmente, varios emplazamientos junto al río Pisuerga, muy cercanos a la antigua vía comercial que ya en la Edad del Hierro permitía conectar la Meseta Norte con la costa. Esta, partiendo del cruce de caminos que controla Dessobriga-Osorno La Mayor/Melgar de Fernamental-, avanzaría en dirección $\mathrm{N}$ siguiendo el curso del Pisuerga, pasando cerca de la ciudad turmoga de Pisoraca, para continuar hacia la Civitas Maggaviensium -Mave, Olleros de Pisuerga, Palencia- y desde allí hacia Monte Bernorio -Villarén de Valdivia, Palencia-, antes de atravesar la cordillera Cantábrica por el camino natural hasta la costa. Desconocemos la casuística de estos campamentos, pero precisamente por lo endeble de su estructura y la similitud con los que se describen a continuación podrían vincularse también con campamentos de entrenamiento. 
156 E. Martín Hernández, A. Martínez Velasco, D. Díaz Alonso et al. / Castrametación romana en la Meseta Norte...

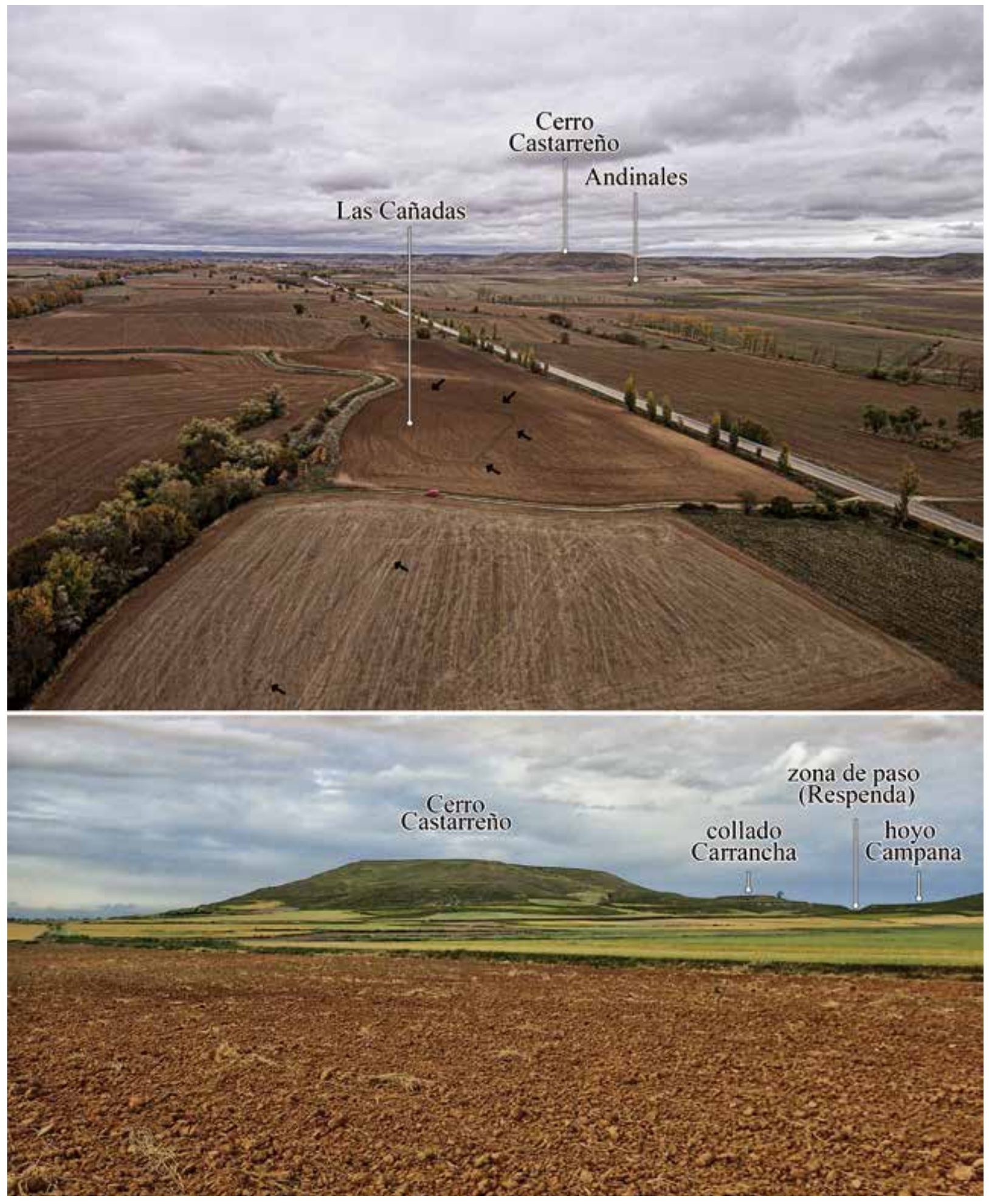

FIG. 5. Arriba: fotografia aérea de Las Cañadas (Villasandino) con el cerro Castarreño al fondo. Abajo: vista a pie de terreno desde el recinto de Andinales. 


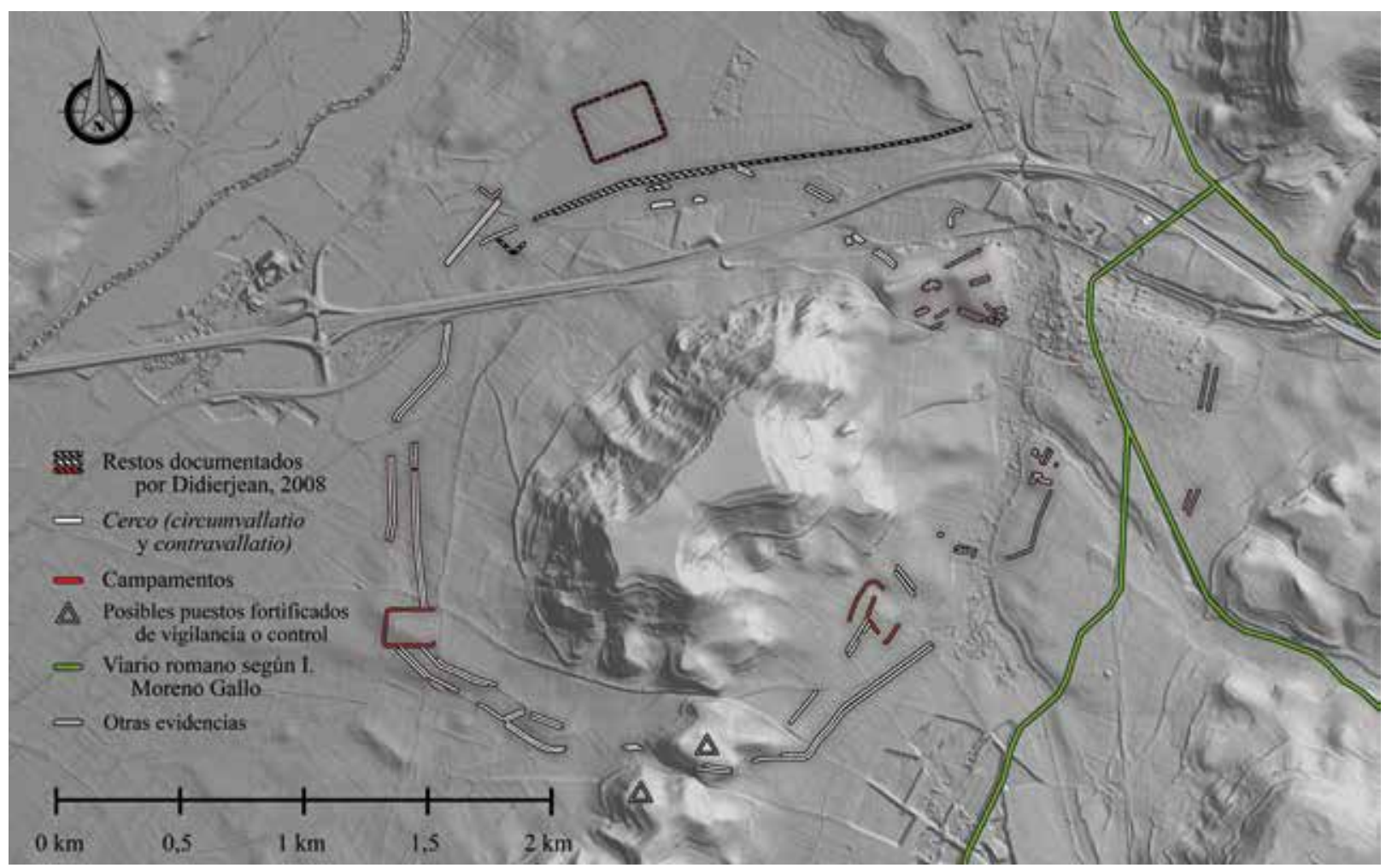

Fig. 6. Desarrollo del cerco alrededor del cerro Castarreño en Olmillos de Sasamón, sobre modelo digital de terreno; en rojo, recintos campamentales reconocidos por Didierjean (Carrecastro y La Veguilla) y recientemente por nuestro equipo; en blanco, fortificaciones del cerco; en violeta, evidencias arqueológicas sin conexión con el sistema de asedio; en verde, vías documentadas por Moreno Gallo (op. cit. n. 12).

En referencia a los recintos del so, a expensas de trabajos sobre los mismos para afianzar su datación, y dada la secular vinculación de este núcleo de población con el ámbito militar romano, puede intuirse la existencia de zonas de entrenamiento de tropas, tal y como parece suceder en el entorno de los campamentos de León ${ }^{12}$, o los bien conocidos de Inglaterra o la zona del norte del Rin. La disciplina y entrenamiento de las tropas fuera de períodos bélicos es siempre necesaria, y la presencia de campamentos de prácticas no es algo anómalo en el mundo romano. Casi todos estos recintos responden ajustadamente a las características que un campamento de entrenamiento presenta (Davies y Jones, 2006: 67 y ss.): tamaños explícitos -en general inferiores a los campamentos en uso-, distancia al

12 Actualmente en estudio por el equipo dirigido por los Dres. A. Morillo y A. Orejas. campamento base; especial atención en la práctica de construcción de elementos primordiales, como esquinas o puertas, que en ocasiones aparecen en número mayor al necesario. En algunos casos, se reconoce la posibilidad de alojamiento de tropas dentro de los mismos (Jones, 2012), punto a demostrar en estos de Herrera.

Los hallazgos de La Ojeda conforman un conjunto diferenciado por su número y por la coincidencia en su establecimiento con la proximidad a un curso de agua, en este caso el río Burejo, en todos los casos en la margen derecha, salvo los posibles de Fresnillo y La Quebrantada ${ }^{13}$. No incluimos

13 Dado que la extensión de este trabajo no lo permite, posponemos la presentación del análisis de estos nuevos establecimientos a posteriores publicaciones que serán realizadas en colaboración con Á. Morillo Cerdán y C. Fernández Ibáñez. 
la descripción de La Charcona por su localización alejada de este grupo junto al río Pisuerga. La comarca de La Ojeda constituye un corredor natural que permite conectar a través de sus ríos y pasos naturales la zona de Segisama con el piedemonte de la cordillera Cantábrica y la ruta que la atraviesa dando acceso a los grandes oppida de la zona como La Loma (Santibánez de La Peńa, Palencia), a través de Herrera de Pisuerga.

En cuanto a la función que cumplen, atendiendo a su establecimiento en un corredor natural, así como al tamaño estimado de algunos como La Calzada o La Fuentecilla, con 4,36 y 7,38 ha respectivamente, y el hallazgo de materiales tardoaugústeos en algunos, caso de los Majuelos o Los Aviles, apuntan hacia una vinculación con el dispositivo militar establecido por la legio IIII Macedonica tras el final de la guerra, para control, entrenamiento e incluso supervisión de las explotaciones mineras (Morillo, 2008: 148-149; Canto et al., 2002).

Caso similar es el de Tortolondro, donde se constata la existencia de varios campamentos superpuestos. Todo parece indicar que se trata de tropas en tránsito, posiblemente hacia Peña Amaya o La Ulaña, puesto que, partiendo de Segisama o Herrera de Pisuerga, ocupa una buena posición en la ruta hacia ambos lugares. La superposición de varios recintos y privilegiada posición de control sobre Peña Amaya apunta precisamente hacia la existencia en el mismo de un punto que actuaría como final de jornada y la existencia de un itinerario o ruta que incluyera varios días.

La identificación de todo un dispositivo de asedio en torno al monte Castarreño -Olmillos de Sasamón, Burgos- vuelve a poner de relieve la importancia de este enclave en el territorio de los turmogos, su papel jugado en el control del territorio y su valor estratégico, que hubo de ser clave durante las guerras cántabras (Fig. 6). La parquedad de las fuentes históricas y lo reducido de los datos disponibles solo permiten realizar una aproximación a su estudio, señalar los datos más relevantes y plantear algunas hipótesis de trabajo como base para un debate posterior.

El monte Castarreño -926 msnm- se define como un cerro exento amesetado, de forma irregular alargada que se extiende en el eje NE-SO, de unas 24 ha. Las laderas presentan fuertes pendientes en todo su perímetro y a sus pies amplios espacios de llanura, tanto por el sur como el oeste, casi hasta la vega del Pisuerga, pero especialmente hacia el norte, donde se localizan las llanuras aluviales de los ríos Odra y Brullés. Domina un extenso campo visual, especialmente hacia el norte, donde alcanza las estribaciones meridionales de la cordillera Cantábrica. El cerro cuenta con un posible sistema de multivallado mediante aterrazamientos que se coordinan y combinan entre ellos, algo relativamente común en el norte peninsular (Torres-Martínez et al., 2016: 71-75). La plataforma superior cuenta, al menos, con una muralla y, ya hacia el extremo norte, se documentó en 2018 un foso transversal que cierra todo ese sector (García Sánchez, 2019: 54-55).

El poblamiento presenta una ocupación intensiva con una secuencia que se inicia en torno a mediados del s. IV a. C. (Ruiz Vélez, 2005: 257) y se extiende a lo largo de toda la II Edad del Hierro, con un final, a partir de los datos aportados por las últimas excavaciones, en el último cuarto del s. I a. C. (García Sánchez y Costa, 2019: 33). Hubo de jugar un papel decisivo en su surgimiento como un gran núcleo de población el control sobre las vías de comunicación que confluyen a sus pies, especialmente las rutas que conectan de este a oeste el sector norte de la meseta y desde aquí con el valle del Ebro, el valle del Duero y la Cornisa Cantábrica. Todo ello convierte Castarreńo en un oppidum que hubo que jugar un papel decisivo en la articulación de un extenso territorio y que a su vez explica la razón que llevó al ejército romano a optar por el establecimiento de un dispositivo de asedio, una costosa opción en términos militares de esfuerzo bélico.

Las evidencias y los datos disponibles a día de hoy son limitados y no permiten extraer conclusiones absolutas, pero sí es necesario y pertinente hacer una aproximación al escenario bélico. Para ello, un enfoque útil es el estudio desde el punto de vista del análisis militar del terreno apoyado en estudios del mismo tipo sobre otros ejemplos conocidos (Brown et al., 2017). Como premisa, la elección del bloqueo -obsidio- como opción para la rendición de una plaza supone que se han descartado otras opciones 
previas como el asalto en marcha -oppugnatio ex itinere-, que se lleva la iniciativa y que se cuenta con efectivos y recursos suficientes, puesto que ello inmoviliza a las tropas durante un período determinado de tiempo y el consumo de recursos que desgastan al propio sitiador, lo que supone, cuando se cuenta con recursos limitados, que paraliza la campaña y la consecución del objetivo, justifica la medida.

Los restos campamentales y estructurales visibles cercando el cerro indican la ejecución de obras de circunvalación -circumvallatio- y el establecimiento de guarniciones intermedias distribuidas en puntos clave. Este tipo de obras remiten a ejemplos como Numancia (Jimeno, 2002; Morillo y Morales, 2016), Alesia (Reddé y von Schnurbein, 2011) o Masada (Davies, 2011), donde se observan unas claves comunes como la ejecución de obras de circunvalación de carácter defensivo que buscan el cierre del perímetro, la adaptación al terreno de las mismas y la distribución e integración o coordinación de los efectivos militares a lo largo de diferentes puntos del cerco.

Con estas construcciones se busca tanto aislar el cerro del exterior y de los recursos más inmediatos, como el agua, como conseguir un control efectivo de los mismos y de las vías principales de comunicación, facilitando labores de logística que garanticen los suministros necesarios para mantener el asedio. El objetivo final puede ser agotar los recursos de la población y conseguir una rendición incondicional - deditio- o bien preparar el terreno para proceder a su asalto -oppugnatio-.

Un cierre completo del perímetro busca también evitar salidas repentinas que rompan el cerco o ataques desde el interior del oppidum. Frente a ello, el establecimiento del dispositivo requiere la distribución de las tropas en puntos clave, apoyándose en diferentes campamentos, de tal forma que todo el perímetro quede cubierto y exista interconexión visual entre ellos. La distribución de fuerzas en el perímetro hubo de ser desigual, reforzándose las zonas de control de aguadas o de los principales accesos del cerro -El Mercado, La Veguilla-.

El emplazamiento de Carrecastro tras la línea de circunvalación permite proponer su naturaleza como base de operaciones desde la que dirigir y

Ediciones Universidad de Salamanca / @థ@्త coordinar todo el operativo. A pesar de que la pauta habitual pase por integrar las fuerzas de asedio directamente en el dispositivo, existen ejemplos de cierta flexibilidad en la disposición de los campamentos, como sucedió en Masada, donde los Campamentos B, C y F1 se dispusieron detrás de la línea de circunvalación, pero en coordinación con el resto (Davies, 2011).

Al hilo de lo anterior, y a pesar de que sin una intervención extensa no es posible determinar con precisión la contemporaneidad de los campamentos y demás estructuras identificadas, la interconexión entre ellas a través de la circunvalación y la posición coherente entre los restos hallados sí permite plantear esta posibilidad (Fig. 7). No sabemos si el objetivo era lograr la rendición por asedio o preparar la toma de la plaza por la fuerza, pero las fuertes pendientes y el sistema de multivallado no ofrecen muchas opciones para el asalto; salvo quizás concentrando tropas y apoyándose en la artillería y el cuerpo de arqueros ${ }^{14}$.

Este dispositivo de asedio, importante obra de ingeniería militar, pone de relieve la importancia estratégica del oppidum de Carrecastro y muestra un aspecto desconocido de la conquista de los turmogos por parte de las tropas romanas. El cerco documentado quizás permite relacionar el monte Castarreño con la Segisama de los turmogos, cerca de la cual estableció Augusto su campamento en el 26 a. C., frente a otras propuestas anteriores que situaban Segisama en Castrojeriz (García Sánchez, 2019: 18-24). Otra posibilidad podría proponerse en la campaña llevada a cabo por T. Statilio Tauro el 29 a. C., quien, según Dión Cassio (LI, 20, 5), luchó contra vacceos, cántabros y astures, preludio de la guerra asturcántabra, y posiblemente estuvo destinada a la conquista de los últimos reductos libres al sur del territorio de los cántabros y astures, así como a controlar las vías de comunicación, para garantizar que toda la retaguardia de la ofensiva posterior

14 Casos similares son los asaltos de La Loma, en Santibáñez de la Peña, Palencia (Peralta, 2015), donde los ataques se dirigen a los accesos principales apoyados por la artillería y, sobre todo, por los arqueros, o de Monte Bernorio, en Villarén de Valdivia, Palencia (Fernández-Götz et al., 2017). 
quedara libre y asegurar el abastecimiento castrense. Una última opción sería vincular este asedio con los triunfos ex Hispania celebrados por C. Calvisio Sabino el 26 de mayo del 28 a. C. (CIL I, 1, 50) o bien el de Sexto Apuleyo el 26 de enero del 26 a. C. (CIL I, 1,77$)$ y que, atendiendo a la fecha de celebración del mismo, debió ser el resultado de una campaña llevada a cabo el año anterior, el 27 a. C.
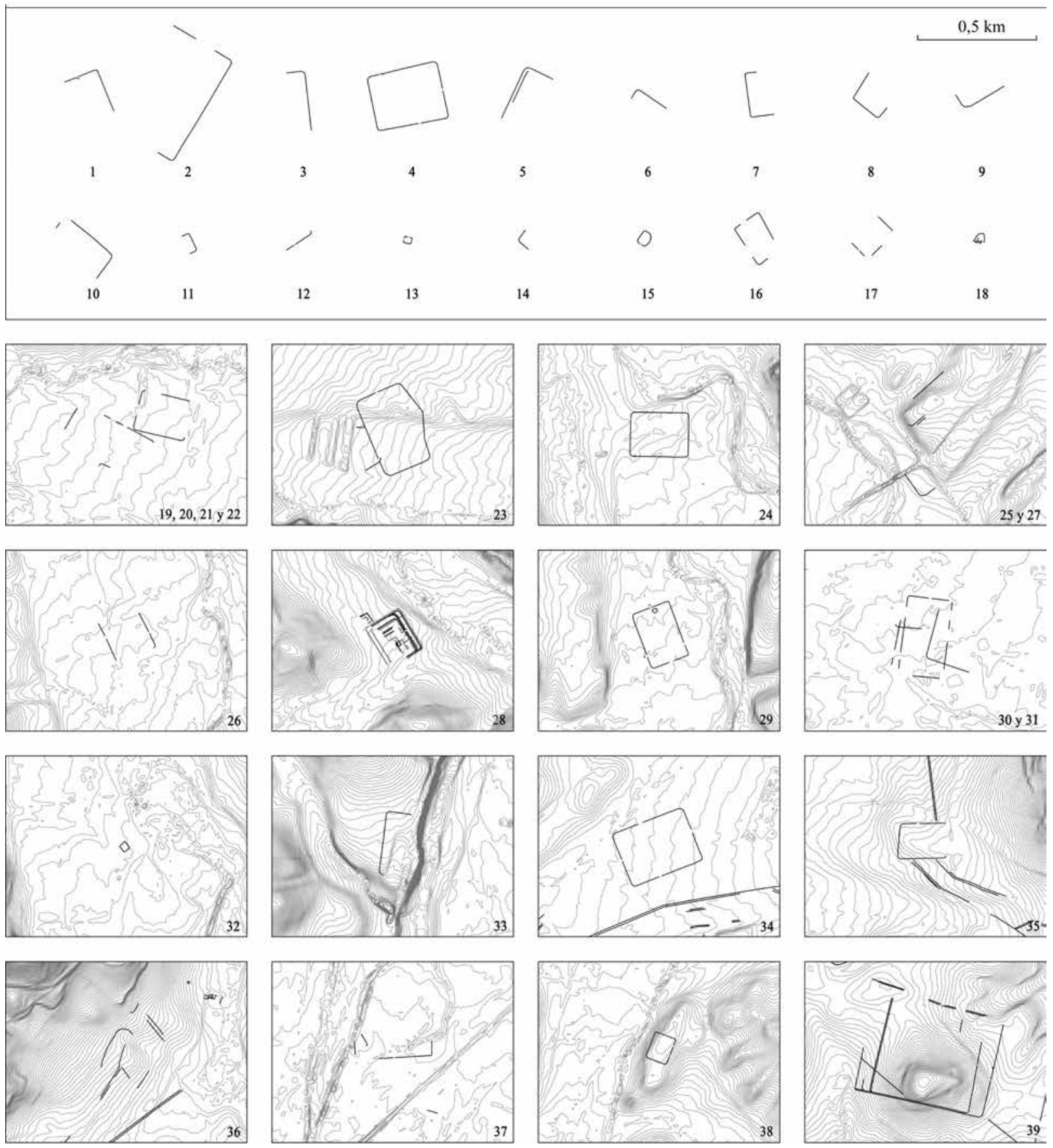

Fig. 7. Desarrollo de las plantas de los diferentes recintos sobre mapa topográfico de curvas de nivel (espaciado 0,5 m) según numeración de la tabla de la Fig. 2; todas las cajas de planimetría tienen una anchura de $1 \mathrm{~km}$. 


\section{Conclusiones}

El trabajo realizado en el marco del Proyecto Roma frente a Cántabros y Astures promovido por la Junta de Castilla y León ha permitido la localización de un variado repertorio de nuevas identificaciones, aún preliminares, para una primera aproximación a su estudio.

Dos cuestiones clave para contextualizar históricamente cada campamento son la cronología y su función. Las características de los recintos observables por teledetección permiten primeras aproximaciones e hipótesis, que requieren forzosamente ser contrastadas en terreno. El establecimiento de dataciones por vías indirectas, como la tipología de la planta de los campamentos, no resulta útil debido a la estandarización de plantas a partir de las reformas de Mario (Morillo y Sala, 2019: 60) y, especialmente, desde mediados del s. I d. C.

Los campamentos temporales localizados al $\mathrm{N}$ de Castilla y León carecen de la regularidad de planta propia de los posteriores, ya que se adaptan a la topografía y a las necesidades concretas en cada caso. Este tipo de asentamientos parecen responder a necesidades de control, como las vinculadas a la extracción minera del o de León, o a la creación y supervisión de las vías, como las de La Carisa o La Mesa, entre León y Asturias. Hasta el momento, los campamentos establecidos para el asedio de castros y oppida seleccionan preferentemente posiciones privilegiadas frente al objeto de asedio, priorizando la localización de ataque frente a la estandarización del emplazamiento. En otros países se han realizado notables panoramas generales de este tipo de asedios y respuestas de los indígenas frente a la conquista (Krausz, 2019) debido al avanzado estado de la investigación.

Lo que resulta evidente, tras un análisis meticuloso de todos ellos, es el mantenimiento de la lógica militar romana. El ejército siempre conservó normas precisas para la erección de espacios castrenses. La inexistencia de partes de la construcción -como la falta de foso en algunos recintos o la duplicación de sistemas defensivos-, así como la modificación de modelos constructivos -desplazamiento de los vanos de entrada o de las calles principales

Ediciones Universidad de Salamanca / 요 dentro del propio espacio-, parece responder a las propias necesidades del momento y no a ninguna cuestión cronológica ${ }^{15}$.

Los campamentos situados alrededor del Monte Castarreño conforman en su conjunto un complejo dispositivo de asedio, lo que, unido al área que ocupa el núcleo indígena hasta ahora inédito, su sistema defensivo, su posición estratégica en las vías de comunicación prerromanas, así como su peso relativo en su entorno geográfico más inmediato, permite proponer la identificación de este lugar como el oppidum turmogo de Segisama. Pero, junto a ello, una de las conclusiones más relevantes es la necesidad de un cambio en el paradigma en torno a la etnia turmoga y su relación con Roma, que debe pasar de una visión pacífica y sumisa a una más ajustada al carácter guerrero de esta sociedad, en coherencia con sus vecinos y con los modelos constatados para las sociedades prerromanas de su época.

Es interesante señalar la elección por Augusto de los alrededores de Segisama como base de operaciones, desde la que iniciar la ofensiva contra los cántabros, en lugar de Dessobriga, controlando el cruce de las vías principales. Posiblemente, esta elección estuvo determinada por los primeros núcleos de población seleccionados para abatir al inicio de la ofensiva romana del 26 a. C., La Ulaña, en Humada, y Peña Amaya, en Amaya, oppida cántabros en la frontera sur del territorio de estos con los turmogos.

Los campamentos del entorno de Herrera de Pisuerga presentan una problemática diferente, que se centra fundamentalmente en la cronología y función de los mismos. El criterio tipológico para el establecimiento de una datación se revela insuficiente. En cualquier caso, sí parece haber un hilo conductor, como es su vinculación a un centro militar como Herrera de Pisuerga y una vía de comunicación de primer orden. Las características generales del conjunto nos impulsan a pensar en zonas de entrenamiento de tropas o centros de asentamiento durante la construcción del viario o de otros centros militares.

15 La existencia de unas líneas maestras que guían la castrametación romana y la variabilidad en su aplicación sobre el terreno condicionada por diferentes circunstancias es una cuestión que ya se observó igualmente en los campamentos romanos de campańa de la Cantabria actual (Fernández-Acebo et al., 2011: 626-633). 
La identificación de varios campamentos jalonando vías de origen prerromano podría así mismo indicar la existencia de puntos de parada de final de jornada en el marco de itinerarios de varias etapas. Con todas las dudas y certezas que ofrece todo este conjunto de nuevos hallazgos, estas identificaciones permiten ampliar las fuentes de información y abrir nuevas vías de investigación.

\section{Fuentes clásicas}

Apiano de Alejandría (1980): Historiae Romanae. Trad. de Sancho, A. (1980). Madrid: edit. Gredos.

Dión Cassio: Historiae Romanae. Trad. de Plácido, D. (2004). Madrid: edit. Gredos.

FLoro (2000): Epitome de Tito Livio bellorum ómnium annorum DCC. Trad. de. Hinojo, G. e Moreno, I. (2000). Madrid: edit. Gredos.

\section{Bibliografía}

Amela, L. (2014): "La conquista del Norte peninsular. Primeros tanteos según las fuentes literarias", Hispania Antiqua, xxxvII-XxxvIII, pp. 68-94.

Ardant du PicQ, C. J. J. J. (1880): Battle Studies: Ancient and Modern Battle. Traducción de Greely, J. N. y Соттоn, R. C. Indiana: Alpha editions, disponible en https://onlinebooks.library.upenn.edu/ webbin/gutbook/lookup?num=7294

BLE, E. (2012): "Aportaciones de la arqueología al conocimiento sobre la historia militar romana", Revista Universitaria de Historia Militar Online, 2, pp. 7-28.

Bohigas, R.; Peralta, E. y Ruiz Vélez, I. (2015): "Un nuevo gran episodio del bellum Cantabricum: el cerco a Peña Dulla (Merindad de Sotoscueva, Burgos)". En Camino, J.; Peralta, E. y Torres-Martínez, J. F. (coords.): Las Guerras Astur-Cántabras. Oviedo, pp. 191-195.

Bolado del Castillo, R.; Gutiérrez Cuenca, E. y Hierro, J. A. (2012): "Las guerras cántabras". En Los Cántabros. Origen de un pueblo. Santander, pp. 95-201.

Brown, C. J.; Fernández-Götz, M.; Torres-MartíNEZ, J. F. y Martínez Velasco, A. (2017): “Fought under the Walls of Bergida: косоA Analysis of the Roman attack on the Cantabrian oppidum of Monte Bernorio (Spain)", Journal of Conflict Archaeology, 12 (2), pp. 115-138.

Camino, J. (2015): "La línea de operaciones de la vía Carisa (Asturias y Norte de León)". En Camino, J.; Peralta, E. y Torres-Martínez, J. F. (coords.): Las
Guerras Astur-Cántabras. Oviedo: KRK Ediciones, pp. 217-237.

Camino, J.; Peralta, E. y Torres-Martínez, J. F. (coords.) (2015): Las Guerras Astur-Cántabras. Oviedo: KRA Ediciones,

Canto, J. C.; Alonso, E.; Matías, R.; Morillo, A. y Neira, S. A. (2002): "Explotaciones auríferas romanas en el Alto Carrión (Palencia, España)". En I Simposio sobre la Minería y Metalurgia antiguas en el Sudeste Europeo. Serós, pp. 333-349.

Chase, A. S. Z.; Chase, D. Z. y Chase A. F. (2017): "LidAR for Archaeological Research and the Study of Historical Landscapes", Sensing the Past, Geotechnologies and the Environment book series (GEOTECH), 16, pp. 89-100.

Costa, J. M.; Menéndez, A.; Fonte, J. y Alonso, F. (2020): "A Penaparda (A Fonsagrada, Lugo-Santalla, Asturias): intervención arqueológica en un recinto campamental romano en el occidente de la cordillera cantábrica". Cuadernos de Estudios Gallegos, LXVII (133), pp. 45-74.

Davies, G. (2011): "Under Siege: The Roman Field Works at Masada", Bulletin of the American Schools of Oriental Research, 362, pp. 65-83.

Davies, J. L. y Jones, R. H. (2006): Roman camps in Wales and The Marches. Cardiff.

Didierjean, F.; Morillo, A. y Petit-Aupert, C. (2014): "Traces de guerres, traces de paix armée: l'apport de quatre campagnes de prospection aérienne dans le nord de l'Espagne". En Cadiou, F. y Navarro, M. (eds.): La guerre et ses traces. Conflicts et Sociétés en Hispanie à l'époque de la conquête romaine (IIIe-Ier siècle av. J. C.). Bordeaux: Ausonius, pp. 149-179.

FernáNDEZ IbÁŃEZ, C. (2007): "La metalistería militar de Hispania en época altoimperial", Sautuola, XIII, pp. 403-425.

Fernández OchoA, C. (coord.) (2003): Gijón, puerto romano: navegación y comercio en el Cantábrico durante la antigüedad. Gijón.

Fernández Vega, P. Á. y Bolado, R. (2011): "El recinto campamental romano de Santa Marina (Valdeolea, Cantabria): un posible escenario de las guerras cántabras. Resultados preliminares de la campaña de 2009", Munibe, 62, pp. 303-339.

Fernández-Acebo, V.; Martínez Velasco, A. y SerNA, A. (2011): "Los poblados fortificados de la Edad del Hierro y las estructuras campamentales romanas en Cantabria: reflexiones sobre el poblamiento, el reparto geográfico y la configuración". En SERNA, J.; Martínez Velasco, A. y Fernández-Acebo, V. (coords.): Castros y Castra en Cantabria. Fortificaciones desde los origenes de la Edad del Hierro a las guerras con Roma. Santander, pp. 589-641.

Fernández-Götz, M.; Torres-Martínez, J. F. y Martínez Velasco, A. (2017): "The battle at Monte Bernorio 
and the Augustan conquest of Cantabrian Spain". En Fernández-Götz, M. y Roymans, N. (eds.): Conflict Archaeology. Materialities of Collective Violence from Prehistory to Late Antiquity, 5, pp. 127-140.

FrancÉs, M. (2011): "Los Turmogos. Revisión de una etnia poco conocida del Norte", ArqueouCA, 1, pp. 31-40.

García Sánchez, J. (2019): "Los Turmogos, sociedad y territorio en los confines del valle del Duero", Vaccea Anuaria, 12, pp. 52-58.

García Sánchez, J. y Costa, J. (2019): "El oppidum del Cerro de Castarreño, Olmillos de Sasamón. Historiografía y arqueología de un hábitat fortificado de la Segunda Edad del Hierro", Boletín de la Institución Fernán González, 98 (258), pp. 9-45.

García y Bellido, A. (1961): "El Exercitus Hispanicus desde Augusto a Vespasiano", Archivo Español de Arqueologia, 34, pp. 114-160.

Jiménez MartíneZ, A. (2002): "Numancia: campamentos romanos y cerco de Escipión”, Archivo Español de Arqueología, 75, pp. 159-176.

Jones, R. H. (2011): Roman Camps in Scotland. Edinburgh: Society of Antiquaries of Scotland.

Jones, R. H. (2012): Roman Camps in Britain. Gloucester: Amberley Publishing.

Krausz, S. (2019): "Gauls under siege: defending against Rome”. En Fitzpatrick, P. y Haselgrove C. (eds.): Julius Caesar's Battle for Gaul, New Archaeological Perspectives. Oxford: Oxbow, pp. 159-178.

Loewinsohn, E. (1965): "Una calzada y dos campamentos romanos del Conventvs Asturvm", Archivo Español de Arqueología, 38, pp. 26-43.

Martín Hernández, E. (2015): "El Mouro. Castrametación en la Vía de La Mesa (Belmonte de Miranda/ Grado, Asturias)". En Camino, J.; Peralta, E. y Torres-Martínez, J. F. (coords.): Las Guerras Astur-Cántabras. Oviedo, pp. 239-245.

Martín Hernández, E. y Camino, J. (2018): "Investigaciones arqueológicas en el cordal de la Carisa. Los campamentos de Llagüezos y La Cuaña de Carraceo". En León, P.: Excavaciones Arqueológicas en Asturias 2013-2016. Gijón, pp. 293-306.

Menéndez, A. y SÁnchez, E. (2018): "Campaña de sondeos arqueológicos en el campamento de época romana del Pico El Outeiro Zarrado (Taramundi-Villanueva de Oscos)". En León, P.: Excavaciones arqueológicas en Asturias 2013-2016. Gijón, pp. 283-292.

MorA, G. (2007): "La Arqueología Militar Romana en España”. En Morillo, Á. (ed.): El ejército romano en Hispania. Guía arqueológica. León, pp. 11-24.

Moreno, I. (2000): Descripción de la vía romana de Italia a Hispania en las provincias de Burgos y Palencia. Burgos-Palencia: Diput. Prov. de Burgos-Palencia.

Moreno, I. (2011): "Vía romana de Segisamone a Pisoraca (de Sasamón a Herrera de Pisuerga)". En Vias
Romanas en Castilla y León. Valladolid: JCYL, pp. 2-28.

Morillo, Á. (2000): "La legio IIII Macedonica en la Península Ibérica. El campamento de Herrera de Pisuerga (Palencia)". En Le Bohec, Y. y Wolf, C. (eds.): IIe Congrés de Lyon sur l'armée romaine. Les légions de Rome sous le Haut Empire. Lyon, pp. 609-624.

Morillo, Á. (2002): "Conquista y estrategia: el ejército romano durante el periodo augusteo y julio-claudio en la región septentrional de la península ibérica”. En Morillo, Á. (ed.): Arqueología militar romana en Hispania. Anejos de Gladius, v. Madrid, pp. 67-94.

Morillo, Á. (2005): "Hispania en la estrategia militar del Alto Imperio: movimientos de tropas en el Arco Atlántico a través de los testimonies arqueológicos". En Fernández Ochoa, C. y García Díaz, P. (eds.): Unidad y diversidad en el Arco Atlántico en época romana. III Coloquio Internacional de Arqueología en Gijón. BAR Internat. Ser., 1371. Oxford: Arcaheopress, pp. 19-33.

Morillo, Á. (2006): "Roman Army and urban development in the Northwest Spain: Asturica Augusta and Legio VII Gemina". En Abad, L.; Keay, S. y Ramallo, S. (eds.): Early Roman Towns in Hispania Tarraconense (II $B C-i^{\text {nt }} A D$ ). Journal of Roman Archaeology Suppl. Ser., 62. Porstmouth, pp. 197-211.

MorILLO, Á. (2008): "La implantación militar romana en el territorio de Cantabria durante el Alto Imperio". En Aja, J. R.; Cisneros, M. y Ramírez, J. L. (eds.): Los cántabros en la Antigüedad. La historia frente al mito. Santander, pp. 142-154.

Morillo, Á. (2012): "Investigación científica y arqueología urbana en la ciudad de León”. En Beltrán, J. y RodríGuez Gutiérrez, O. (eds.): Hispaniae urbes. Investigaciones arqueológicas en ciudades históricas. Sevilla: pp. 211-256.

Morillo, Á. (2014): “Arqueología de la conquista del norte peninsular. Nuevas interpretaciones sobre las campañas del 26-25 a. C.”. En Cadiou, F. y NAvarro, M. (eds.): La guerre et ses traces. Conflicts et Sociétés en Hispanie à l'époque de la conquête romaine (IIIe-Ier siècle av. J. C.). Mémoires, 37. Bordeaux: Ausonius, pp. 133-148.

Morillo, Â.; Adroher, A.; Dobson, M. y Martín Hernández , E. (2020): "Constructing the archaeology of the Roman conquest of Hispania: new evidence, perspectives and challenges", Journal of Roman Archaeology, 33, pp. 35-52.

Morillo, Á. y García Marcos, V. (2006): "Legio (León). Introducción histórica y arqueológica”. En García-Bellido, M. ${ }^{\text {a }}$ P.: Los campamentos romanos en Hispania (27 a. C.-192 d. C.). El abastecimiento de moneda. Anejos de Gladius, 9. Madrid, pp. 225-243.

Morillo, A. y Morales, F. (2016): "Campamentos romanos de la guerra de Numancia: la circunvalación 
escipiónica”. En Bendala, M. (ed.): Los Escipiones. Roma conquista Hispania. Alcalá de Henares: pp. 275-297.

Morillo, Á.; Pérez González, C. e Illarregui, E. (2006): "Herrera de Pisuerga (Palencia). Introducción histórica y arqueológica. Los asentamientos militares". En García-Bellido, M. ${ }^{a}$ P. (ed.): Los Campamentos Romanos en Hispania (27 a. C.-192 d. C.). Anejos de Gladius, 9. Madrid, vol. 1, pp. 305-323.

Morillo, A. y SAla, F. (2019): "The Sertorian Wars in the conquest of Hispania: from data to archaeological assesment”. En Fitzpatrick, A. P. y Haselgrove, C. (eds.): The Archaeology of Caesar in Britain and Gaul. New archaeological perspectives. Oxford-Philadelphia, pp. 49-72.

Nuño, J. (1990): "Poblamiento de época romana en el valle de La Ojeda (Palencia)". En Calleja, M. V. (coord.): Actas II Congreso de Historia de Palencia. Vol. 1, Prehistoria, Arqueología e Historia Antigua. Palencia, pp. 245-274.

Orejas, A.; Sánchez-Palencia, F. J.; Beltrán, A.; Ron, J. A.; López, L. F.; Currás, B. X.; Romero, D.; Zubiaurre, E.; Pecharromán, J. L. y Arboledas, L. (2015): "Conquista, articulación del territorio y explotación de recursos en el límite entre el convento lucense y el de los astures (Proyecto IVGa)". En Camino, J.; PeralTA, E. y Torres-Martínez, J. F. (coords.): Las Guerras Astur-Cántabras. Oviedo, pp. 247-260.

Orejas, A.; Sánchez-Palencia, F. J.; Currás, B. X.; Ron, J. A. y López, L. F. (2019): “Campamentos militares durante la primera ocupación romana del Noroeste de la Península Ibérica”. En VAllori, B.; Rueda, C. y Bellón, J. P. (eds.): Accampamenti, guarnigioni e assedi durante la Seconda Guerra Punica e la conquista romana (secoli III-I a. C.): prospettive archeologiche. Roma: ediz. Quasar.

Peralta, E. (1999): "El asedio romano del Castro de la Espina del Gallego (Cantabria) y el problema de Aracelium", Complutum, 10, 195-212.

Peralta, E. (2000): Los Cántabros antes de Roma. Bibliotheca Archaeologica Hispana, 5, Madrid: RAH.

Peralta, E. (2001): "Los castra aestiva del bellum cantabricum: novedades arqueológicas". En Actas Ier Congreso Internacional de H. ${ }^{a}$ Antigua. Valladolid, pp. 173-182.
Peralta, E. (2002): "Los campamentos romanos de campaña (castra aestiva): evidencias científicas y carencias académicas", Nivel Cero, 10, pp. 49-87.

Peralta, E. (2015): “El asedio de La Loma (Santibáñez de la Peńa, Palencia) y otros campamentos romanos del Norte de Castilla”. En Camino, J.; Peralta, E. y Torres, J. F. (coords.): Las Guerras Astur-Cántabras. Oviedo: KRK, pp. 91-109.

Peralta, E.; Hierro, J. A. y Gutiérrez, E. (2011): “Las monedas de los campamentos romanos de campaña de las guerras cántabras del asedio de La Loma, Castillejo y El Alambre", Lucentum, 30, pp. 151-172.

Quesada, F. (2014): "Novedades y líneas de investigación recientes en la arqueología militar de la Iberia Prerromana. Una aproximación bibliográfica”. En MArTínez Ruiz, E. y Cantera, J. (dirs.): Perspectivas y novedades de la Historia Militar. Una aproximación global. Madrid: Ministerio de Defensa, pp. 59-92.

Reddé, M. y Von Schnurbein, S. (dirs.) (2011): Alésia. Fouilles et recherches franco-allemandes sur les travaux militaires romains autour du Mont-Auxois (1991-1997). Mémoire de l'Académie des Inscriptions et Belles-Lettres, 22. Paris.

Ruiz Vélez, I. (2005): "La Edad del Hierro en Las Loras y el interfluvio Pisuerga-Arlanzón (Burgos) (II)”, Boletín de la Institución Fernán González, 85 (231), pp. 255283.

SÁnChez-Palencia, F. J. (1986): "El campamento romano de Valdemeda, Manzaneda (León): ocupación militar y explotación aurífera en el Nw peninsular", Numantia, 2, pp. 227-235.

Torres-Martínez, J. F.; Fernández-Götz, M.; Martínez Velasco, A.; Cabanillas, G.; Vacas, D. y Martín, E. (2016): "Las fortificaciones protohistóricas del área cantábrica: aspectos defensivos, sociales y simbólicos”, Gallaecia, 34, pp. 57-82.

VidAl, J. y GonzÁlez, M. L. (2018): “Asturica Augusta: actualización de su urbanismo a la luz de las excavaciones recientes”. En Martínez Caballero, S.; SAntos, J. y Municio, L. (eds.): El urbanismo de las ciudades romanas del valle del Duero. Anejos de Segovia Histórica, 2. Segovia, pp. 273-297.

Durante la corrección de pruebas de este artículo, hemos tenido noticia de la publicación reciente en la revista Geoscience, 10 (noviembre de 2020), de otro trabajo en el que se presenta información derivada del Proyecto Roma frente a Cántabros y Astures, encargado por la Junta de Castilla y León a la primera firmante conjuntamente con los recintos leoneses que se encuentran en prensa por parte del equipo de A. Orejas y Á. Morillo, ambos englobados en proyectos de investigación auspiciados por la Junta de Castilla y León. Los informes resultantes de las diferentes intervenciones arqueológicas, aún inéditos, se encuentran depositados en esa institución y, hasta el momento, solo se había entregado el original correspondiente a este artículo para su valoración y publicación en Zephyrus. Por ello, desde la Dirección de esta revista quiere dejarse constancia de la notable preocupación que ha generado esta situación. 